\title{
Editorial
}

\section{Donald Mavinic}

Professor, University of British Columbia, Vancouver, Canada

It is my pleasure to introduce our international readership to the December 2014 issue of the Journal of Environmental Engineering and Science (JEES). You will notice that only three peer-reviewed papers made it to press time; several additional papers are still in the editorial process and could not make our editorial deadline. However, these three papers clearly represent the breadth of publishing envisioned for JEES when relaunched a few years ago.

The first paper, by Yu et al. (2014), deals with the concept of radiation fields associated with an LED photoreactor. LED technology is advancing rapidly in the environmental use field, and the authors have successfully managed to develop and test a radiation field model, a model that shows promise in designing a more efficient photoreactor for use in the environmental science and engineering fields - an excellent contribution.

The second paper, authored by Yang et al. (2014), presents the results of a study into use of microbial desalination cells for both desalination and the production of hydrogen peroxide. The authors are to be commended for pursuing this novel desalination approach, using a biocatalyst with the ability to convert organic waste to bioenergy, for subsequent use in desalinating salty water. Well done.

The third paper, written by Radu et al. (2014), represents a completely different subject area, one closer to my own research interests. This paper presents the results of a 2-year case study of anaerobic digestion of brewery wastewater in the UK. The digestion process involves the use of an expanded granular sludge bed reactor, in conjunction with a newly available method for volatile fatty acid analysis; this method proved ideal as a rapid, onsite, operational indicator of reactor stability. This approach has significant implication for industrial waste treatment and technology transfer.

As the world's population rapidly accelerates to 8 billion, over the next 10 years, it is easy to see that environmental issues will increase in importance. In the January 2002 issue of JEES (Volume 1, Issue 1), Dan Smith and yours truly, as the original co-editors, penned a message to the readers that is as relevant now as it was 12 years ago.

The need for a better understanding of the scientific facts and the principles is growing exponentially. This new knowledge must be translated into tools and guiding principles, which will, hopefully, reduce the impact that this tremendous population increase will have. New and more wisely engineered systems are needed to address the long-term impacts (Smith and Mavinic, 2002).

When ICE Publishing decided to relaunch JEES about 3 years ago, Dan Smith and I were not only thrilled by this decision, we were also very pleased that about two-thirds of the original editorial board agreed to remain with JEES. Subsequently, about six to seven new international associate editors were added, the result being that the current board is one of the strongest and most diverse of any of the environmental journals currently being published. Earlier this year, Dan was forced to step down as co-editor because of family reasons but remains associated with JEES in various promotional capacities. Early in 2015, likely by early February, I will also step aside as senior editor and turn over the reins of JEES to Dr Norman Neumann, from the University of Alberta. Norman is an excellent choice to lead JEES into the next phase of its relaunch, the goal being to receive and publish sufficient peer-reviewed papers to allow ICE Publishing to approve six issues per year, once again. I will remain a member of the editorial board.

I personally ask all of you to not only continue to support JEES but also to 'spread the word' and encourage new and promising researchers in the environmental area to regularly submit manuscripts to JEES. It has been a very rewarding 3-4 years working with Dan, ICE Publishing and many on the current board, to bring JEES back into the publishing limelight - the future of JEES is in good hands. Thank you for your continuing support.

\section{REFERENCES}

Radu T, Blanchard R, Smedley V, Theaker H and Wheatley A (2014) Monitoring anaerobic digestion: a 2-year brewery case study. Journal of Environmental Engineering and Science 9(4): 206-212. 
Yu L, Achari G and Langford CH (2014) Design a homogeneous radiation field in an LED photo-reactor. Journal of

Environmental Engineering and Science 9(4): 213-222.
Smith DW and Mavinic DS (2002) Editorial. Journal of Environmental Engineering and Science 1(1): iii-v. Yang E, Choi M-J, Kim K-Y and Kim IS (2014) Microbial desalination cell for concurrent hydrogen peroxide production and desalination. Journal of Environmental Engineering and Science 9(4): 196-205. 